\title{
Socioeconomic issues of United States military neurosurgery
}

\author{
Commander Ross R. Moquin, MC USNR, AND \\ Lieutenant Colonel James M. ECKLund, MC USA \\ National Capital Consortium Neurosurgery Program, Washington, D.C.
}

\begin{abstract}
Although the practice of neurosurgery in the United States (US) Armed Forces is in many ways similar to the civilian practice of neurosurgery, there are many differences as well. The unique challenges, duties, and opportunities US military neurosurgeons are given, both in peacetime and in times of conflict, are discussed, as are pathways for entering into service. The advantages of military service for neurosurgeons include sponsored training, decreased direct exposure to tort actions, little involvement with third-party payers, significant opportunities for travel, and militaryspecific experiences. The most appealing aspect of military practice is serving fellow members of the US Armed Forces. Disadvantages include the extreme gap between the military and civilian pay scales, lack of support personnel, and in some areas low surgery-related case volume. The greatest concern faced by the military neurosurgical community is the failure to retain experienced neurosurgeons after their obligated service time has been completed, for which several possible solutions are described. It is hoped that future changes will make the practice of military neurosurgery attractive enough so that it will be seen as a career in itself and not an obligation to endure before starting practice in the "real world."
\end{abstract}

\section{KEY WORDS • military neurosurgery • hospital ship • combat support hospital • pay gap • retention • aeromedical evacuation}

\section{SOCIOECONOMIC ASPECTS OF UNITED STATES MILITARY NEUROSURGERY}

The US Department of Defense has three uniformed service branches in which neurosurgeons are on active duty. These surgeons are all commissioned officers in the US Army, Navy, and Air Force. Currently, the Air Force has eight active neurosurgeons, the Army has 17, and the Navy has 14. During peacetime, military neurosurgeons are primarily responsible for preserving the fighting strength-this refers to maximizing the health and numbers of uniformed service members who are available and ready to perform their designated duties. Military neurosurgeons treat all types of neurosurgical disease, even if the service member is not subsequently capable of returning to full duty. The peacetime mission also includes treating all Department of Defense beneficiaries, including dependents of active-duty members, retirees and their dependents, national leaders, and selected foreign dignitaries. In certain select circumstances, Department of Defense neurosurgeons also provide support to the Veterans Administration hospitals.

The military neurosurgeon's practice is in many ways similar to that involving most civilian neurosurgeons

Abbreviations used in this paper: ISP = Incentive Specialty Pay; $\mathrm{MTF}=$ military treatment facility; US = United States. throughout the US. The majority of new patient-related interactions (nearly 80\%) involve treating routine spinal pathological entities. Lumbar and cervical disc herniations commonly occur in active troop and fleet units. Degenerative diseases of the spine are also observed in the more senior active-duty and retired populations. Spinal deformities are found primarily in recruits, dependents, and patients who have suffered traumatic injury. The incidence of brain tumors is the same as that in the general population. The exposure to trauma and cerebrovascular diseases varies because of referral patterns and the trauma center designation of the military MTF. Department of Defense MTFs include one Level one and three Level two trauma centers.

Military neurosurgeons are also deployed with the forces. Uniformed neurosurgeons are continuously stationed outside the US in Japan and Germany. Additionally, neurosurgeons are deployed closer to the war fronts when heavy concentrations of forces are actively engaged in or preparing for combat operations. Neurosurgeons can be assigned to a hospital platform, such as a Combat Support Hospital, fleet hospital, or one of the two hospital ships. In the Army they are often deployed as K-teams consisting of two neurosurgeons, anesthetists, critical care nurses, surgical technicians, neurosurgical equipment, instrument sets, and vehicles. The K-team is designed to be mobile so that it can augment an already deployed field 
hospital, depending on the tactical situation and medical needs. Except in unique circumstances, neurosurgeons are only deployed with computerized tomography scanning capabilities and the more robust hospital configurations, according to current doctrine. The most recent hostile areas to which neurosurgeons have been sent are Somalia (1992-1993) and Haiti (1994). ${ }^{3}$ During the Persian Gulf War there were approximately 40 neurosurgeons deployed into the theater of operation. Military neurosurgeons have more recently been on alert for potential deployments in a number of regions including the Balkans and Afghanistan.

The US military has more neurosurgeons on active duty than any other nation. Our neurosurgeons routinely treat service members from allied forces in the US and overseas. In times of conflict, members of opposing forces will also be treated in addition to noncombatants affected by the conflict. Recently, during the Persian Gulf War, US neurosurgeons deployed to the theater of operations performed a substantial number of procedures in Iraqi prisoners and local civilians (Figs. 1 and 2).

All branches of US military neurosurgeons are also occasionally deployed in support of humanitarian and diplomatic missions called operations. This involvement can be either as a primary mission or an adjunct to a training exercise. Recent threats to our homeland security can also be expected to result in additional requirements for military neurosurgeons to assist in local mass casualty exercises and collaborative efforts with local civilian institutions. Recent examples include a Navy neurosurgeon who was with the hospital ship USNS Comfort T-AH 20 when she was deployed to New York Harbor to augment medical capabilities, and two Army neurosurgeons who directly assisted at the Pentagon after the attacks of September 11, 2001. In 1998, during a training exercise in the Baltic Sea (Baltic Challenge '98), a 14-year-old Lithuanian boy underwent a successful resection of a very large and disfiguring occipital lipomyeloencephalocele, which was performed aboard the USNS Comfort while underway.

Since the Persian Gulf War and with Force 21 consid-

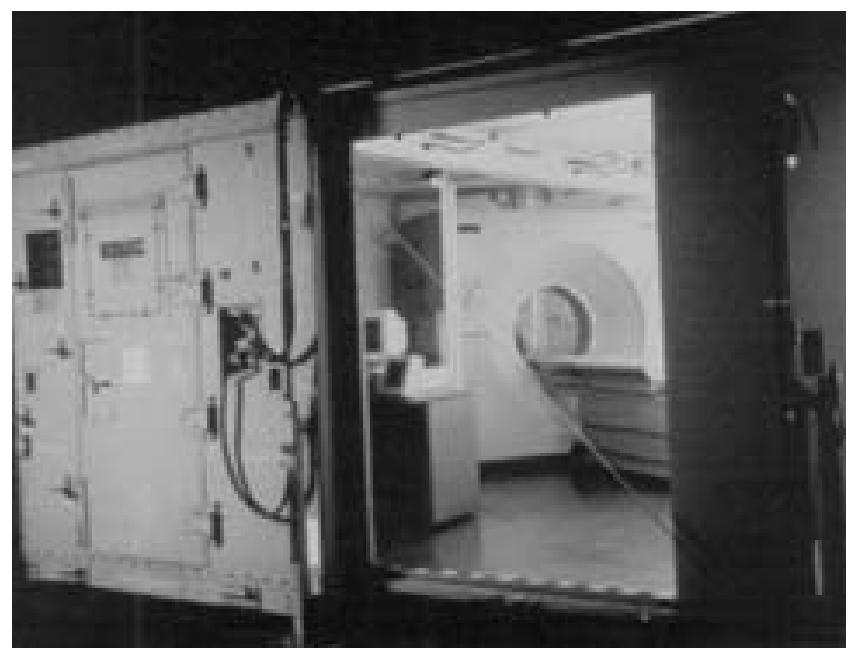

Fig. 1. Photograph demonstrating portable field-hardened computerized tomography scanner. Current military medical doctrine deploys neurosurgeons forward only when scanners such as this are readily available.

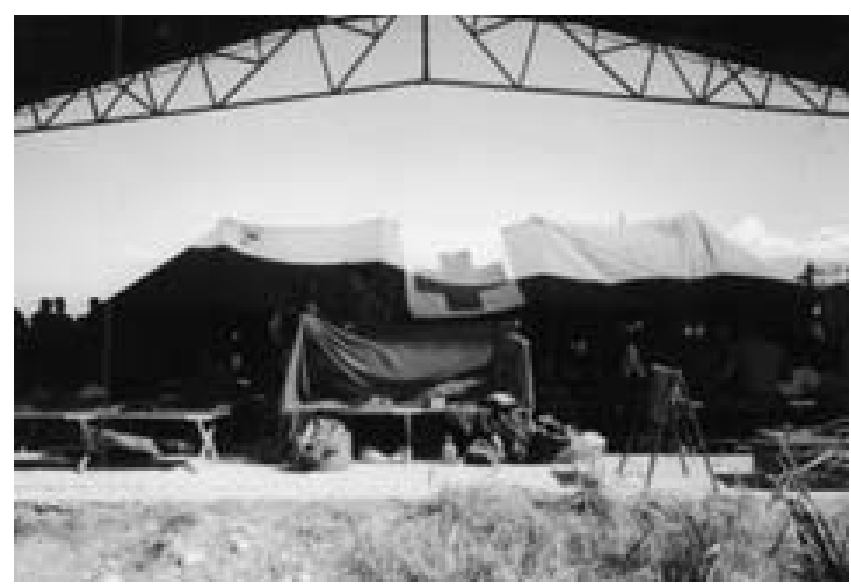

Fig. 2. Photograph showing 5th Mobile Surgical Hospital, Port au Prince Airport, Haiti, October 1994. This unit was the first landbased medical facility operational in Operation Restore Democracy.

erations, war-fighting doctrines have been undergoing revisions. As a result of these changes, the medical support of deployed forces is also in evolution. There is now a greater emphasis on early rearward evacuation of the more severely injured casualties to larger facilities. This will likely decrease the far-forward deployment of neurosurgeons. ${ }^{2}$

As the preceding discussion indicates, one invariable aspect of military life is readiness, or training for the warfighting mission. Medical support is a major part of any combat mission and is therefore a major part of any training exercise. Neurosurgeons are often called to participate in the larger training exercises. These may involve US military units alone or joint operations involving allied nations. Training takes place both within the US and throughout the world. The Navy routinely sends neurosurgeons in support of operations such as Kernal Blitz and Cobra Gold in the Pacific and operation Baltic Challenge, a joint exercise with many of the prior Warsaw Pact nations (Figs. 3 and 4).

Another duty assigned to the military, especially those stationed in the Washington, D.C., area is the care of the national leaders. Members of the House of Representatives, Senators, Supreme Court Justices, Cabinet Members, the President, and Vice President are treated in the MTFs. Neurosurgeons at Walter Reed Army Medical Center and National Naval Medical Center, Bethesda, are frequently involved in the care of these leaders of government. At times, neurosurgeons are called on to travel with some of these leaders if a significant threat is considered possible. Occasionally foreign national leaders are also treated by the uniformed neurosurgeons when requested by the President or the Department of State.

Other duties assigned to military neurosurgeons include administrative tasks in neurosurgical departments and assisting with command activities. Although most neurosurgeons remain clinically oriented their entire careers, a few elect to pursue command tracks. There is currently an Army hospital commander at Fort Stewart in Savannah, Georgia, who is a neurosurgeon. In the recent past there was a Navy hospital Commanding Officer at the Naval 


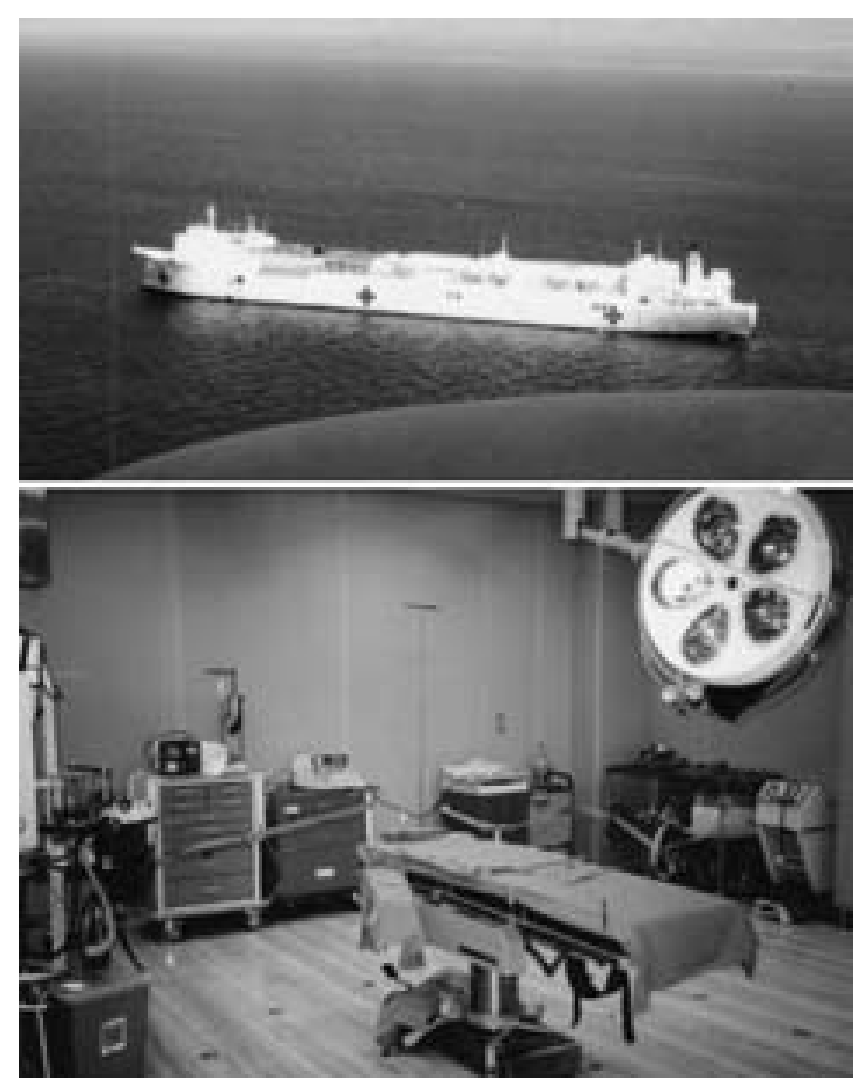

Fig. 3. Upper: The USNS Comfort T-AH 20 off the coast of Haiti, October, 1994. The photograph was taken from a US Army Blackhawk Medivac helicopter on final approach for landing on her flight deck. Lower: Neurosurgical operating room aboard the USNS Comfort. Capabilities exist for most neurosurgical procedures including craniotomies for trauma, microsurgical aneurysm clipping, and placement of spinal instrumentation at all levels. All equipment is secured to the deck or bulkhead in preparation for ocean transit.

Hospital, Rota, Spain, and in the 1980s the Air Force's overall Medical Commander, the Surgeon General, was a neurosurgeon.

\section{ACQUISITION OF NEUROSURGEONS}

There are several pathways to becoming a military nerosurgeon, the most common of which results from training obligation. The Health Professional Scholarship Program is responsible for the majority of active-duty military neurosurgeons. In this program, the medical school years of training are financed and a stipend paid by the US military. In return, the student will then serve the equivalent number of years on active duty. Another route to military neurosurgery is through the Uniform Services University of the Health Science, at which all medical students are on active duty in the Army, Navy, Air Force, or Public Health Service. There is no tuition and students receive a full 2LT or ensign salary. In exchange, students serve a 7-year service obligation after completion of residency training. Another path is full-time out-of-service sponsorship for residency or fellowship training. In this program the resident or fellow is on active duty, although he/she is assigned to a civilian program, while receiving

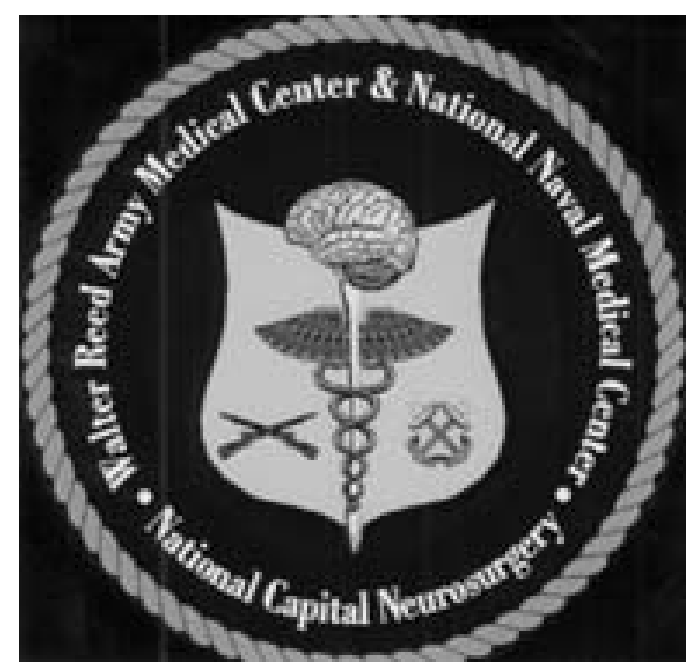

Fig. 4. Unit Seal of the National Capital Neurosurgery Residency Program.

full pay, benefits, and rank. The service obligation incurred for this program is 1 year on active duty serving as a neurosurgeon for every year of sponsored residency or fellowship.

The National Capital Consortium Neurosurgery Program was formed in 1996 from the consolidation of the Neurosurgical Residency Training Programs at Walter Reed Army Medical Center in Washington, D.C., and the National Naval Medical Center, Bethesda, Maryland. This is a tri-service accredited program that graduates one resident each year. Residents in this program are on active duty during training and must serve at least 2 years on active duty as neurosurgeons after completion. Usually the obligation is longer due to prior training such as Health Professional Scholarship Program or University of the Health Science. The National Capital Consortium Neurosurgery Residency Program is the only neurosurgery training site in which the Military Unique Curriculum is a formal required part of the training (Fig. 4).

Although it is possible for a neurosurgeon to enter active duty in the US Military without a training obligation, this is rarely occurs. In the last 15 years there have been two such cases. Recruiting Commands have found it nearly impossible to recruit fully trained neurosurgeons directly. The reasons for this difficulty will be discussed in the next section in which retention is addressed.

There has been considerably more success in obtaining neurosurgeons willing to serve in the reserve forces. Reserve neurosurgeons serve part time and can be called up for active duty in times of national crisis. The reserve ranks are filled both by patriotic neurosurgeons who have volunteered and by those who are able to serve selected service obligations in the reserves. Many of these neurosurgeons have previously participated in military service. The most recent call to active duty of reserve neurosurgeons occurred during the Persian Gulf War.

\section{RETENTION OF NEUROSURGEONS}

Retention of active-duty, experienced, productive neurosurgeons has historically been extremely difficult. Al- 
though many outstanding neurosurgeons have come through the military, they rarely stay beyond their training commitment. The high quality of military neurosurgeons is clearly reflected by their career paths after leaving active service. Many leaders of neurosurgery, both in the academic and the private practice arenas, have begun their neurosurgical careers in uniform.

There are many reasons why neurosurgeons do not continue to serve the military once their service obligation for training has ended. The most obvious is the extreme pay gap between the standard civilian neurosurgery practice and military practice. When an active-duty uniformed neurosurgeon finishes residency training, he/she becomes a major in the Air Force and Army, or a lieutenant commander in the Navy, and his/her total pay and allowances is approximately $\$ 100,000$ per year. If that neurosurgeon serves a full 20-year career and advances to full colonel or Navy captain, then he/she can expect a yearly salary of approximately $\$ 150,000 .{ }^{1} \mathrm{He}$ or she can then retire with a pension of approximately $\$ 40,000$ to 45,000 per year, which is then adjusted for inflation. ${ }^{1}$ From data obtained from 2001 the MGMA Physician Compensation and Production Survey and the 2001 MGMA Academic Practice Faculty Compensation and Production Survey, the median salary of a private-practice neurosurgeon in the US is $\$ 410,593$. The median salary for a neurosurgeon in an academic position is $\$ 275,000$. According to Physician Search, an online medical manpower recruiter, in 2000 the mean salary for all neurosurgeons at least 3 years out of training practicing in the US was $\$ 438,000$.

Military pay is broken down into three components. Basic Pay, the base salary for any military officer, is based on rank and time in service. Two bonuses include Medical Specialty Pay, which is $\$ 15,000$ given yearly to all physicians, and ISP, which is an additional bonus based on medical specialty. The ISP is currently $\$ 36,000$ for neurosurgeons. A third bonus option is the Multi-year Additional Specialty Pay, which ranges from $\$ 8,000$ to 14,000 per year for those who agree to remain in uniform 2 to 4 years beyond any prior service obligation. There are also nontaxable allowances such as Basic Allowance for Subsistence, Basic Allowance for Quarters, and Variable Housing Allowance, which provide additional funds for housing in areas in which the cost of living is higher than average. For those that live overseas and are affected by currency fluctuations, there is Cost of Living Allowance that changes every 2 weeks based on the exchange rate between the US dollar and the local currency. All military members receive the same allowances based on rank and duty station. Other benefits include the aforementioned retirement plan, free health care, reasonable dental and life insurance packages, and a newly authorized thrift savings retirement plan option. Unfortunately, all the neurosurgeryrelated professional fees, organizational dues, and journals, must be paid by the individual neurosurgeon, further decreasing the military neurosurgeon's actual salary.

Prior to the mid-1980s all military officers were paid approximately the same for rank and time in service. Largely through the work of neurosurgeons Captain Robert Harris, MC USN(ret), and Colonel Eugene George, MC USA(ret), the ISP described was instituted to decrease the wide pay gap that made retention impossible, especially for the surgical subspecialties. The actual pay total was varied based on the subspecialty and the relative need for that subspecialty throughout the services. Congress mandated that the highest yearly amount any specialty group could receive was $\$ 36,000$. The bonus pay did serve to improve morale within the neurosurgical ranks, but in reality it was inadequate to bridge the wide pay gap. Neither recruitment nor retention was significantly improved. Since that time many other subspecialties have received increases in the ISP to the maximum rate. Because this maximum rate has not increased over the last 15 years, most surgical subspecialists and many nonsurgeons currently receive the same level of compensation as the neurosurgeon. One decade ago the Army had 28 practicing neurosurgeons on active duty; today, because of retention difficulty, there are 17 .

When there is a shortage of neurosurgeons in service, contracts are given to civilian neurosurgeons. These contracts are usually quite reasonable, as yearly salaries range from $\$ 300,000$ to 400,000 . Although essential for the delivery of care, these contracts frequently have a detrimental effect on morale for the uniformed neurosurgical personnel. Civilian-contract neurosurgeons often have restricted duty hours and fewer administrative duties, no readiness requirements, and no deployment responsibilities despite the fact that they receive substantially higher reimbursement.

Another factor affecting the retention of neurosurgeons in the Armed Forces is the lack of support personnel, such as nurses, physician assistants, and administrative assistants. Because military neurosurgeons must complete many routine clerical duties themselves, their efficiency as surgeons is decreased compared with their colleagues in the civilian world. The average civilian neurosurgeon performs approximately 250 procedures a year. In the military most neurosurgeons perform only 100 to 200 procedures. This is largely the result of operating room time limitations and the decreased support infrastructure, which burden the neurosurgeon with routine administrative obligations associated with the care of each patient. Typically there are three to four support personnel per each neurosurgeon in an efficient civilian practice. In many military treatment facilities, one clerical person supports two to four neurosurgeons. Neurosurgeons frequently type their own letters and clean their own examination rooms. Although these duties clearly need to be performed, a neurosurgeon can be much more efficient if allowed to spend more time directly care for patients. Such inefficiencies are detrimental to the morale of neurosurgeons who have been trained to be very efficient and effective. Recent experience at Walter Reed Army Medical Center revealed that with the addition of physician assistants, nurse practitioners, and nurse case managers, the efficiency of the neurosurgical service increased dramatically without an increase in the number of neurosurgeons. In most medical communities, neurosurgeons are seen as revenue generators and accordingly are provided with support infrastructure. The fixed budgetary realm of military medicine is sometimes challenged by the expense of supporting complex neurological services with equipment and personnel. Fortunately, the hospital commanders uniformly desire to provide quality state-of-the-art care to all the patients, and the military neurosurgeon will generally be supported in efforts to obtain equipment and resources. 
Although the slow bureaucratic processes remain a frequent source of dissatisfaction, most MTFs at which neurosurgeons practice are superbly equipped with state-ofthe-art equipment and instrumentation.

More recently, surgery-related case volume has become an issue in some military hospitals. Because the new TRICARE program of care and because of a fleet of aging medical transport aircraft, some neurosurgical cases traditionally performed in military MTFs have been undertaken instead by civilian neurosurgeons. This process has evolved differently depending on locations and has contributed to downsizing and even eliminating neurosurgical care at some military hospitals. In a few isolated instances, newly graduated military neurosurgeons have found difficulty accumulating adequate cases to qualify for the oral boards. Low case volume also has implications regarding maintenance of competency. Just as the aviators must keep flying to hone their skills, neurosurgeons must perform a reasonable number of procedures to maintain surgical capabilities. In some isolated commands, the issue may be more related to a lack of operating room availability than patient caseload.

With decreased retention there are fewer individual neurosurgical bodies to meet operational and deployment requirements, which increases the deployment rate for those few on active duty, resulting in more time spent away from family and practice. Some deployment and overseas assignments can be seen as desirable, but others are significantly less desirable. Many neurosurgeons consider the increased deployment tempo a significant disincentive to being in the military.

At present there are only three O-6 (colonel in Army and Air Force or captain in Navy) neurosurgeons on active duty, of whom only one is in full-time clinical practice. Because no neurosurgeons stay beyond their training obligation and because those with training obligations come right after training, only 12 of the 38 active-duty neurosurgeons are board certified. Clearly, the military lacks adequate staffing with senior neurosurgeons who offer the complex and critical corporate knowledge of military neurosurgical experience. The Society of Medical Consultants to the Armed Forces strives to bring that experience and expertise to the Army, Navy, and Air Force Surgeons General. This is a dedicated group representing experienced senior military and civilian physicians from all specialties who meet annually to advise the Surgeons General and senior service leadership on military medicalrelated matters. A number of civilian neurosurgeons and one active military neurosurgeon are currently members of this society.

Despite some of the socioeconomic challenges that make retention of military neurosurgeons difficult, there are many attractive benefits. The greatest benefit is the patient population. As a group, military service members are hard working, selfless, and extremely well motivated. These traits are significantly different from those commonly found in the civilian Workers' Compensation population of the US. Because they are an all-volunteer force, most are on active duty by choice and desire to complete their service until retirement or honorable discharge. The honorable individuals and the regimented healthy lifestyle make active-duty service members excellent candidates for surgery, thereby ensuring that surgery is more pleasant for the surgeon. Most active-duty neurosurgeons report the profound feelings of loyalty, respect, and honor toward the active-duty service members as the greatest positive intangible factor for active-duty service. These feelings are greatly amplified during times of national emergency and when treating service members entering or returning from hostile areas. These deep-rooted feelings of loyalty and service to the warfighters were clearly manifested after the events of September 11, 2001, when the leaders of the three services received many calls from retired and former active-duty neurosurgeons offering to leave civilian practice and return to active-duty status.

Malpractice insurance is not the obtrusive issue it is in civilian practice, although the military does respond to and interact with the National Practitioner Data Bank. As officers and agents of the government, military neurosurgeons are not personally named in civil tort action. All tort actions are filed against the government. At every MTF there is a vigorous quality-assurance program that continuously works to improve patient-related care and identify potential problems before they occur. The military neurosurgeon is subject to The Uniform Code of Military Justice that puts forth a set of rules and regulations to which all military members must adhere. Additionally, there are specific rules for procurement of equipment, interaction with vendors, acceptance of gifts, etc.

Billing issues are also not nearly as onerous in the military system. Although a third-party collection process is currently in place, the military neurosurgeon is much less affected than his/her civilian counterparts for whom extensive resources are often tied up by billing and insurance interactions.

Furthermore, military neurosurgeons have opportunities that are not readily available to their civilian counterparts. Global travel and military-specific activities such as airborne training, military aviation, field activities, and sea deployments are desired and unique opportunities of military life. Overseas tours in which several years are spent in another culture while practicing neurosurgery are not typically offered in any other setting.

Neurosurgeons interested in research have unique opportunities within the military as well. They may champion and conduct research designed to advance the care of patients on the battlefield and in remote environments. A number of military-unique questions are resourced and investigated such as those related to duty limitations postoperatively, the practice of neurosurgery within an environment of limited resources, and CNS injuries resulting from emerging weapons systems.

Difficult to categorize, but extremely important, are the intangible military service-related factors that are not found in civilian practice. As a military neurosurgeon, one is involved in an enterprise much larger than oneself. During times of national crisis, he/she is directly involved in meeting the needs of the nation and, in some cases, those of the world. Patriotism takes on a new and immediate meaning when one wears the military uniform. The terms "shipmate" and "brothers in arms" have very special meaning to those who serve together in difficult times and dangerous places. Out of shared hardship and danger grows a strong sense of comraderie not found elsewhere. The bonds formed on or around the battlefields or at sea are some of the strongest of human relationships, fully 
understood only by those involved. Deployed neurosurgeons become full members of the warrior culture, thus sharing the experiences and emotions of the warfighters. Caring for combat-injured service members is an incredible privilege and responsibility, which has been reported by current and retired neurosurgeons as among the most rewarding and emotional experiences of their careers. For those who served in the military at the start of their neurosurgical careers, their senses of patriotism and brotherhood evoke their fondest memories.

\section{POTENTIAL FUTURE CONSIDERATIONS}

The aforementioned pay gap and support issues are the greatest problems affecting retention and recruitment of neurosurgeons in the Armed Forces. The Army, Navy, and Air Force Surgeons General are all working incredibly hard to address these issues. Tri-service efforts such as the National Capital Consortium Neurosurgery Program between Walter Reed Army and National Naval Medical Centers allow a concentration of resources and efforts, providing economies of scale. In addition to the Surgeons General working with Congress to improve current reimbursement, other incentives such as including bonus pays in retirement calculations are also being considered.

In select cases local commanders may consider establishing relationships with community universities or practices to permit the sharing of both personnel and equipment. If a military hospital sees the need to maintain active-duty neurosurgeons on staff, but if the caseload is suboptimum, perhaps an arrangement can be made in which the military neurosurgeon can practice part time at the civilian institution; in some scenarios this might result in some additional reimbursement for the military neurosurgeon. This win-win strategy could provide the neurosurgeon with improved competence and readiness for the military, as well as offer welcome coverage assistance to the local hospital or university. It might also contribute to a financial and practice environment attractive enough to entice some neurosurgeons to remain in the military beyond their obligations. Our soldiers, sailors, airmen, and marines, and their families, deserve experienced, highquality neurosurgical care, and our young military neurosurgeons deserve mentoring from senior neurosurgeons. We must develop a strategy by which to attract and retain a cadre of devoted, experienced neurosurgeons within the Armed Forces. Strong graduate medical education programs with associated service obligations are certainly helpful with acquisition, but retention remains a critical issue (Fig. 5).

\section{CONCLUSIONS}

There will always be a need for neurosurgeons in the uniformed services. Career military neurosurgeons should be encouraged and supported. The goal is long-term program building provided by stable faculty. Military neurosurgery has been and should continue to be a leader in advancing the field and training the young neurosurgeon, both as residents and junior attending staff.

It is a privilege and honor to serve with the men and

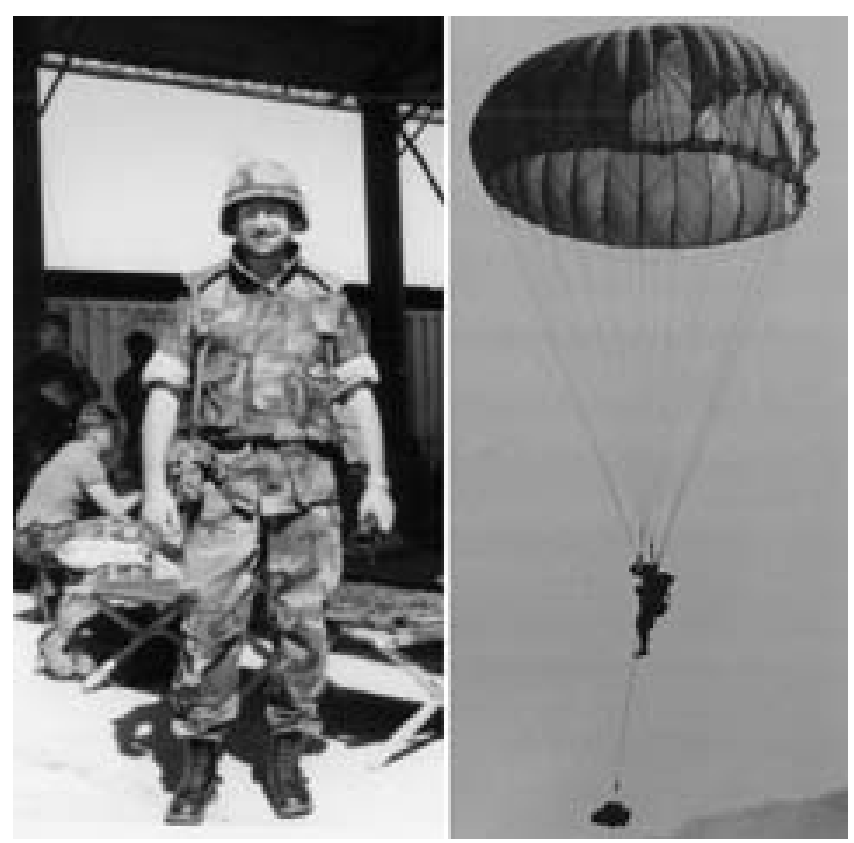

Fig. 5. Left: Commander Ross Moquin (Port au Prince, Haiti October 1994) prepared to move from the secured compound of the 5th Mobile Surgical Hospital to a more forward medical position. Right: Lieutenant Colonel James Ecklund during one of his many Airborne jumps with medic pack containing neurosurgical equipment.

women of the US military. Although there are challenges, the experience is wonderful and noble. The military patients deserve to have the best possible health care, both in peacetime and at war. Thus, we need to have the best that neurosurgery has to offer in terms of technology and surgical experience. Military neurosurgery should be made attractive enough so that it will be desired as a career unto itself and not an obligation to endure before starting practice in the "real world."

\section{References}

1. Army Times. January 14, 2002

2. Bowen TE, Bellemy RF (eds): Emergency War Surgery. Second United States Revision of the Emergency War Surgery NATO Handbook. Washington, DC: US Government Printing Office, 1988

3. Ecklund JM, Moquin RR, Ling G: Technology from the military: pre-hospital and battlefield care, in Howard MA, Cobbs CS, Elliott JP, et al (eds): Clinical Neurosurgery: Vol 48. Philadelphia: Lippincott Williams \& Wilkins, 2001, pp 174-180

Manuscript received February 25, 2002.

Accepted in final form March 26, 2002.

The opinions and views expressed in this article are those of the authors and do not reflect the official policy or position of the US Navy, US Army, Department of Defense, or US Government.

Address reprint requests to: CDR Ross R. Moquin, MC, USNR, Neurosurgery Service, Ward 64, Walter Reed Army Medical Center, Washington, D.C. 20307-5001. email: RossMoquin@aol.com. 